\title{
State-level wage Phillips curves
}

\author{
George Kapetanios ${ }^{\mathrm{e}}$, Simon Price ${ }^{\mathrm{a}, \mathrm{b}, \mathrm{c}, \mathrm{d}}$, Menelaos Tasiou ${ }^{\mathrm{f}}$, and Alexia Ventouri*e \\ ${ }^{a}$ Essex Business School, UK \\ ${ }^{\mathrm{b}}$ City University of London, UK \\ ${ }^{\mathrm{c}}$ Money Macro and Finance (MMF) Society, UK \\ ${ }^{\mathrm{d}}$ Centre for Applied Macroeconomic Analysis (CAMA), Australia \\ 'King's College, University of London, UK \\ ${ }^{\mathrm{f}}$ University of Portsmouth, UK
}

March 20, 2020

\begin{abstract}
Based on US state-level data for the period 1982-2016, two reduced-form versions of New Keynesian wage Phillips curves are examined. These are based on either sticky nominal wages or real-wage rigidity. The endogeneity of unemployment is taken into account by instrumentation and the use of common correlated effects (CCE) and mean group (MG) methods. This is the first time that this methodology has been applied in this context. These are important issues, as ignoring them may lead to substantial biases. The results show that while the aggregate data do not provide estimates that are consistent with either of the theoretical models examined, the panel methods do. Moreover, use of an appropriate MG CCE estimator leads to economically significant changes in parameters (primarily a steeper Phillips curve) relative to those from inappropriate but widely used panel methods. In the real-wage rigidity case, this is required to deliver results that have a theoretically admissible interpretation.
\end{abstract}

Keywords: Wage Phillips curves, state-level data, panel estimation, CCE.

\section{Introduction}

Phillips (1958) uncovered an empirical relationship between (UK) wage inflation and unemployment, spanning the period between 1861 and 1957. The eponymous curve has subsequently remained firmly at the heart of macroeconomics in both wage and price inflation space. Phillip's original exercise was purely empirical, but theoretical interpretations with a simple excess-demand mechanism followed. Since then theory has changed, with expectations and various forms of nominal or real rigidity playing crucial roles in the current New Keynesian incarnations, which lie at the heart of modern DSGE models. The curve is uniquely important in the conduct of monetary policy as, without it, prices are flexible and monetary policy has no role. The parameters and specification of the Phillips curve are therefore of huge interest, not only from a purely academic view but also from the perspective of optimal policy. Most estimates are undertaken using aggregate data, and where disaggregated data have been used, the specifications tend not to have a modern structural interpretation. As will be explained in more detail below, this may be highly important. Estimated aggregate specifications where there are heterogeneous disaggregate dynamic relationships are subject to aggregation bias. Moreover, no disaggregated studies address all the relevant econometric issues (including heteroegeneity of parameters, common correlated effects and endogeneity of regressors). Our paper addresses these deficiencies.

*Corresponding Author's Mailing Address: King's Business School, 30 Aldwych, WC2B 4BG, London, UK. E-mail Addresses: sgprice@essex.ac.uk (S. Price), george.kapetanios@kcl.ac.uk (G. Kapetanios), menelaos.tasiou@port.ac.uk (M. Tasiou), alexia.ventouri@kcl.ac.uk (A. Ventouri). 
In the remainder of this introduction, we relate our work to the Phillips curve literature, briefly allude to the econometric issues and cite some related work, none of which take the comprehensive approach we adopt in this study.

\subsection{Phillips curves}

Although now more usually associated with price inflation, the original Phillips curve explained wage inflation. Phillips fitted his eponymous curve with a bespoke method suggesting that a non-linear relationship between nominal wage inflation and the level (but also the change) of unemployment existed in the UK. He presented it as a type of regularity, rather than as a theoretical relationship. Lipsey (1960) used more conventional methods to estimate the relationship and introduced price inflation as an explanatory variable. In these versions driven by a market excess-demand adjustment mechanism, it was odd that the specification was one of rates of change in wages, when the underlying idea was one of adjustment to an equilibrium wage; a tension that still remained in the Phelps (1967) and Friedman (1968) notion of the expectations augmented Phillips curve. Some later specifications in this tradition, such as the NAIRU interpretation exposited at length in Layard et al. (1991), were based on wage and price setting where unemployment, productivity and other factors determine the longrun real wage.

The Phillips curve in its modern New Keynesian configuration (the NKPC) is by contrast the forward-looking relationship between price inflation and marginal costs. The latter is often proxied by real unit labour costs, or a capacity measure such as the output gap or unemployment, presumed to be correlated with marginal costs. In this interpretation, the driver is not excess demand but marginal cost, and the specification may be seen as either price/wage setting, demand for labour or supply of output: all are derived from the same maximisation problem. Marginal cost may be measured directly or by some assumed related proxy for excess demand (the output gap or unemployment). The specification exploits the recursive nature of the dynamic problem to generate a specification that looks similar to a traditional Phillips curve (in its 'expectations-augmented' form, e.g. Phelps, 1967), although the interpretation is different. The relationship is so well-known as to hardly require a reference, but Woodford (2003) is a common citation for an exposition. Interest has been maintained by policymakers as the relationship between activity, wages and prices is a key part of the inflationary process. Similarly, the wage Phillips curve in macro models is typically also modelled as a forward-looking process with staggered wage setting or other rigidities, and has the same interpretation. At the heart of the relationship is a relative price, the real wage or real labour costs. As Galí (2011) notes, there has been less empirical attention to the wage setting process than to prices, which he hoped to partially rectify by specifying and estimating a New Keynesian Wage Phillips Curve (NKWPC), and it is this approach that we follow.

\subsection{Econometric issues}

What is missing, however, is a recognition that labour markets are local. From the beginning, some of the literature on Phillips curves considered the relationship to be a consequence of aggregation over specific markets in varying excess demand (Hansen, 1970; Evans, 1985), but recently, it has only infrequently been considered. This is important, because despite the fact that it is often ignored, in general, aggregation has a large impact on the dynamics of aggregate relationships in the presence of heterogeneity at the disaggregate level, typically leading to more persistence. Robertson and Symons (1992) spell out why there is distortion of the dynamics from aggregation; Imbs et al. (2005) is an example of an application to the real exchange rate where the consequences of ignoring aggregation are profound. In another highly pertinent paper, Imbs et al. (2007) explores the implications of ignoring heterogeneity on aggregate dynamics in the context of French industry level data.

In this paper, we seek to address this issue, as well as to estimate theoretically well-motivated models, specifically Augmented New Keynesian Wage Phillips Curves due to Galí (2011) and Orlandi et al. (2017). We use US state-level data to estimate the average dynamic process, more relevant in structural models than likely biased 
estimates derived from aggregate data. As we spell out in more detail below, we also take account of the existence of common correlated effects, which are known to be important empirically in panels of the type we examine (see Phillips and Sul, 2003), and allow for endogeneity among the regressors. This -often neglectedendogeneity arises straightforwardly from the simultaneity of wages and (un)employment. There is a second source of endogeneity from forward-looking expectations but there is no need to be addressed here as our reduced-form substitutes out future expectations.

\subsection{Previous studies}

As noted above, previous panel and sectoral estimates exist indeed, yet this specific and important exercise has not been conducted before on any set of panel data. M J Luengo-Prado and Sheremirov (2017) examine US sectoral inflation. Leduc and Wilson (2017) examine city-level relationships. Smith (2014) examines the effect of labour market slack on wages at state level. More closely related, the model in Kumar and Orrenius (2014) is based on the traditional Phillips curve approach, with an emphasis on non-linearity, and focuses on pooled estimates. A rare example of a panel approach to the NKPC (not the NKWPC) is that of Byrne et al. (2013). They use an MG panel approach to the NKPC using data for 14 geographically and economically dispersed countries accounting for cross-sectional heterogeneity to a limited extent, but not endogeneity. They look at a group of countries whose aggregate has no special meaning, whereas US states are connected via trade, free movement of labour, geographical contiguity, culture and a common monetary and fiscal framework. Finally, Aaronson and Sullivan (2000) use similar data to ours, but perform simple pooled regressions.

\subsection{Our aims}

Briefly, we estimate reduced-form versions of New Keynesian Wage Phillips curves using state-level data and appropriate techniques allowing for endogeneity, heterogeneity and common correlated effects; an exercise, which has not been previously undertaken. Moreover, we estimate relationships that are firmly rooted in the modern macroeconomic theory of price and wage adjustment, the New Keynesian Phillips Curve. State-level data offers a rich data set that may make it possible to improve our understanding relative to aggregate data, even if it is solely the aggregate relationship which we are interested in. This is potentially important, as it is well-known that aggregation can seriously distort estimates of dynamic processes such as wage adjustment and may thus lead to misleading inferences that affect how macroeconomic policymakers (e.g. the FRB) respond to shocks. There has been previous research on state-level labour markets and wage determination, but none of these take into account the econometric problems arising from heterogeneous dynamics, endogeneity between wages and labour market excess demand and from common correlated disturbances. Additionally, this is equally problematic from the point of view of those wishing to understand local labour markets. We find that when we use appropriate techniques, the results are substantially different from those obtained using conventional methods. The results on balance favour a forward-looking New Keynesian specification with nominal rigidities put forward by Galí (2011).

The next section sets out two specifications for the Augmented NKWPC. We describe the econometric methodology in Section 3, and provide a summary of our data and a description of our results in Section 4. Finally, Section 5 concludes.

\section{The New Keynesian Wage Phillips Curve}

The standard New Keynesian Phillips Curve (NKPC) is a forward-looking approach to price setting that exploits the recursive nature of the dynamic problem to generate a specification that looks similar to a traditional Phillips curve, although the interpretation is quite different. Similarly, there are forward-looking models of staggered wage setting that have similar properties. Galí (2011) set out an analytical structure for what he termed a New 
Keynesian Wage Phillips Curve (NKWPC). Using his notation, his Equation (13) is

$$
\Delta w_{t}=\beta E_{t}\left\{\Delta w_{t+1}\right\}-\lambda_{w} \varphi \hat{u}_{t}+\varepsilon_{t}
$$

where $w_{t}$ is the $(\log )$ nominal wage, $u_{t}$ is unemployment, $u_{n}$ the natural rate and $\hat{u}_{t}=u_{t}-u_{n}$ is the deviation from the natural rate. Here and in the empirical work we assume -as Galì does- that $u_{n}$ is constant. A more detailed discussion is provided in Section 4.2. $\varphi$ determines the marginal disutility of work and $\beta$ is the rate of time discount. With wage indexation, the ANKWPC is

$$
\Delta w_{t}=\alpha+\gamma \Delta p_{t-1}+\beta E_{t}\left\{\Delta w_{t+1}-\gamma \Delta p_{t}\right\}-\lambda_{w} \varphi u_{t}+\varepsilon_{t}
$$

(his Equation (14)), where $p_{t}$ is a measure used for price indexation. $\lambda_{w}=\frac{\left(1-\theta_{w}\right)\left(1-\beta \theta_{w}\right)}{\theta_{w}\left(1+\epsilon_{w} \varphi\right)}>0$, where $\epsilon_{w}$ is the wage elasticity of demand for labour (that determines the wage mark-up) and $\left(1-\theta_{w}\right)$ is the Calvo-style probability that wages are reset each period. $\alpha=(1-\beta))\left((1-\gamma) \pi^{p}+g\right)$ where $\pi^{p}$ is steady state inflation, $g$ is the steady state rate of growth of productivity and $\gamma$ is the weight of steady state inflation in the indexation formula. Not all of these structural parameters can be recovered from the NKWPC or ANKWPC without other equations but their plausibility can be assessed using calibration. $\beta$ and $\gamma$ are identified.

\subsection{Backward specifications}

Galí (2011) shows that if we assume (the deviation of) unemployment (from the natural rate) follows an AR(2) such that

$$
u_{t}=\phi_{1} u_{t-1}+\phi_{2} u_{t-2}+\varepsilon_{t},
$$

then the reduced-form wage equation corresponding to (2.2) is

$$
\Delta w_{t}=\alpha+\gamma \Delta p_{t-1}+\psi_{0} u_{t}+\psi_{0} u_{t-1}+\varepsilon_{t}
$$

The underlying parameters are not all uniquely identified, but

$$
\begin{aligned}
& \psi_{0} \equiv-\frac{\lambda \varphi}{1-\beta\left(\phi_{1}+\beta \phi_{2}\right)}, \\
& \psi_{0} \equiv-\frac{\lambda \varphi \beta \phi_{2}}{1-\beta\left(\phi_{1}+\beta \phi 2\right)} .
\end{aligned}
$$

Orlandi et al. (2017) present a related model with real wage rigidities (RNKWC). Here

$$
\Delta w p g_{t}=\alpha+\beta \gamma \Delta w p g_{t+1}+(1-\gamma) \Delta w p g_{t-1}-\lambda_{w} \varphi u_{t}+\varepsilon_{t}
$$

where $\Delta w p g_{t}=\Delta w_{t}-\Delta p_{t}-g_{t}$ and $g_{t}$ is the growth in trend productivity. The backward version is similar to Galí's:

$$
\Delta w p g_{t}=\alpha+\beta_{0} \Delta w p g_{t-1}-\psi_{0} u_{t}-\psi_{1} u_{t-1}+\varepsilon_{t} .
$$

Here $\beta_{0}=\frac{\beta}{1+\frac{(\theta-1) \phi}{\gamma(1-p h i)}}$, where $\beta$ is the discount factor (assumed close to and less than one), $\theta$ is the elasticity of substitution of labour, $\gamma$ is a wage adjustment parameter and $\phi$ is the degree of real-wage inertia that lies between 0 and 1. As in Galí (2011) and Orlandi et al. (2017), it is these backward specifications we estimate.

\section{Estimation methodology}

Panels conventionally have dimensions $T$ and $N$ in time and the cross-section. Traditionally, panel techniques were developed for cases where $T$ is short -often very short- and $N$ large, so that pooling of parameters is essential for estimation. Nickell (1981) pointed out that this led to biases in dynamic panels deriving from the 
initial conditions that are severe for short T. The response, following Anderson and Hsiao (1982) and developed in Arellano and Bond (1991) and subsequent papers, was to introduce GMM methods. By contrast, in panels (such as ours) where $T$ and $N$ are of of similar magnitudes and where $T$ is long enough the Nickell bias is negligible. However, as Pesaran and Smith (1995) pointed out, if there is heterogeneity in the parameters across units, there is another bias that is also potentially large. This is because if there is heterogeneity pooling the parameters of interest (say $\beta_{i}$ on the variable $z_{i t}$ ) introduces an error into the residual which is composed of the product of the difference between the true and pooled parameter and each of the variables (in this case $\left(\beta_{i}-\beta\right)_{i t}$ where $\beta$ is the pooled parameter), immediately introducing endogeneity. This cannot be instrumented using lagged variables due to the dynamic process. Their simple proposal, the mean-group (MG) estimator of the average effect that simply takes the mean of individual unit estimates. The MG estimator is unbiased, but may not be the most efficient. Pesaran et al. (1999) subsequently proposed the pooled-mean-group (PMG) estimator for cases where some or all of the parameters may efficiently be pooled. In particular, in the proposed Hausman-type test for poolability, the null is best thought of as the PMG estimator being an efficient and unbiased estimator, rather than that the $\beta_{i}=\beta$.

Another general source of bias is the presence of unobserved common processes across the units, or cross-sectional dependence (CSD), surveyed in Chudik and Pesaran (2015). It is possible -in fact likely- that these exist. That is, there are common factors, possibly unobserved, that affect all units in a panel, so that the covariance of the errors is unlikely to be zero. A further problem then is that the cross-sectional dependence arising from e.g. an unobserved common shock, may be correlated with regressors. Phillips and Sul (2003) discuss the consequences of this and conclude they are likely to be profound, so that pooling offers only marginal benefits in efficiency, and parameter estimates may be subject to large biases. Although recognised and modelled in spatial econometrics, this was not considered in conventional panel techniques until relatively recently. A natural way to deal with this is to assume a common factor structure and then estimate those factors, for example using principal components (PC), but this raises the issues of identifying correctly and estimating the number of factors, and is problematic if factors are correlated with the explanatory variables. Coakley et al. (2006) examined a range of estimators, and as Chudik and Pesaran (2015) observe, PC-estimated factor models are subject to problems.

However, Pesaran M. H. (2006) introduced the common correlated effects (CCE) methodology for the estimation of large- $T$ panels, which is simple to apply, has good properties and is not subject to mis-specification of the number or weights of the factors. Kapetanios et al. (2011) show that it is appropriate with multiple I(0) or I(1) factors, which may be correlated with regressors and in the presence of autocorrelated errors. It is therefore this approach that we adopt.

In particular, we consider the general model

$$
\begin{gathered}
y_{i t}=\beta_{0 i}+\beta_{1 i} y_{i, t-1}+\boldsymbol{\beta}_{2 i}^{\prime} \boldsymbol{x}_{i t}+\boldsymbol{\beta}_{3 i}^{\prime} \boldsymbol{z}_{i t}+u_{i t} \\
u_{i t}=\boldsymbol{\lambda}_{i}^{\prime} \boldsymbol{f}_{t}+\epsilon_{i t} \\
\boldsymbol{x}_{i t}=\pi_{i}+\boldsymbol{\Pi}_{i} \boldsymbol{z}_{i t}+\boldsymbol{\Lambda}_{i} \boldsymbol{f}_{t}+\boldsymbol{v}_{i t}
\end{gathered}
$$

where the $y_{i t}$ are endogenous variables to be explained, $\boldsymbol{x}_{i t}$ are other potentially endogenous explanatory variables, and $\boldsymbol{z}_{i t}$ are exogenous variables. $\boldsymbol{f}_{t}$ are unobserved interactive effects and $\boldsymbol{\lambda}_{i}$ are factor loadings. Finally, $\boldsymbol{\Lambda}_{i}$ is a factor loading matrix with fixed and bound components, and $\boldsymbol{v}_{i t}$ are the specific components of $\boldsymbol{x}_{i t}$ distributed independently of the common effects and across $i$, but assumed to follow general covariance stationary processes.

We assume that $\epsilon_{i t}$ and $\boldsymbol{v}_{i t}$ are correlated for given $i$, but uncorrelated across $i$, and are martingale difference processes over time as is $u_{i t}$. Chudik and Pesaran (2015) discuss the use of cross-sectional average proxies to augment (3.1) and estimate its coefficients. In particular, due to the presence of the lagged dependent variable in (3.1), they suggest that the cross-sectional averages at time $t$, i.e. $\bar{y}_{t}$ (where $\bar{y}_{t}=\frac{1}{N} \sum_{i=1}^{N} y_{i t}, N$ being the 
number of cross-sectional units), $\overline{\boldsymbol{x}}_{t}$ and $\overline{\boldsymbol{z}}_{t}$ (similarly computed) and their lags be used to augment (3.1). Then, either pooled or mean-group panel estimation may be carried out. If $\epsilon_{i t}$ and $\boldsymbol{v}_{i t}$ are correlated, one needs further to instrument $\boldsymbol{x}_{i t}$ by some appropriate instrument $\boldsymbol{w}_{i t}$ as discussed in Harding and Lamarche (2011). Note that since $\epsilon_{i t}$ and $\boldsymbol{v}_{i t}$ are uncorrelated across $i$, the endogeneity does not affect the cross-sectional average proxies. In particular, letting $\boldsymbol{R}_{i}=\left(\boldsymbol{y}_{i}, \boldsymbol{X}_{i}, \boldsymbol{Z}_{i}\right), \boldsymbol{W}_{i}=\left(\boldsymbol{y}_{i,-1}, \boldsymbol{W}_{i}, \boldsymbol{Z}_{i}\right), \boldsymbol{y}_{i}=\left(y_{i, 2}, \ldots, y_{i, T}\right)^{\prime}, \boldsymbol{y}_{i,-1}=\left(y_{i, 1}, \ldots, y_{i, T-1}\right)^{\prime}$ $\boldsymbol{X}_{i}=\left(\boldsymbol{x}_{1}, \ldots, \boldsymbol{x}_{m_{x}}\right)^{\prime} \boldsymbol{x}_{i}=\left(x_{i 2}, \ldots, \boldsymbol{x}_{i T}\right)^{\prime}, \boldsymbol{Z}_{i}=\left(\boldsymbol{z}_{1}, \ldots, \boldsymbol{z}_{m_{z}}\right)^{\prime} \boldsymbol{z}_{i}=\left(z_{i 2}, \ldots, \boldsymbol{z}_{i T}\right)^{\prime}, \boldsymbol{W}_{i}=\left(\boldsymbol{w}_{1}, \ldots, \boldsymbol{w}_{m_{w}}\right)^{\prime} \boldsymbol{w}_{i}=$ $\left(w_{i 2}, \ldots, \boldsymbol{w}_{i T}\right)^{\prime}$ and $\boldsymbol{M}=\boldsymbol{I}-\boldsymbol{P}\left(\boldsymbol{P}^{\prime} \boldsymbol{P}\right)^{-1} \boldsymbol{P}^{\prime}$ where $\boldsymbol{P}$ contains the cross-sectional proxies and a constant, the pooled estimator is given by

$$
\left(\begin{array}{c}
\hat{\beta}_{1 i} \\
\hat{\beta}_{2 i} \\
\hat{\beta}_{3 i}
\end{array}\right)=\left(\sum_{i=1}^{N}\left[\boldsymbol{R}_{i}^{\prime} \boldsymbol{M} \boldsymbol{W}_{i}\left(\boldsymbol{W}_{i}^{\prime} \boldsymbol{M} \boldsymbol{W}_{i}\right)^{-1} \boldsymbol{W}_{i}^{\prime} \boldsymbol{M} \boldsymbol{R}_{i}\right]\right)^{-1}\left(\sum_{i=1}^{N}\left[\boldsymbol{R}_{i}^{\prime} \boldsymbol{M} \boldsymbol{W}_{i}\left(\boldsymbol{W}_{i}^{\prime} \boldsymbol{M} \boldsymbol{W}_{i}\right)^{-1} \boldsymbol{W}_{i}^{\prime} \boldsymbol{M} \boldsymbol{y}_{i}\right]\right)
$$

It is this methodology that we apply.

\section{Data description \& Results}

In this section, we give a description of the data and its sources (Subsection 4.1), and report the results of estimating our two New Keynesian Wage Phillips Curve specifications with aggregate (Subsection 4.2) and disaggregate (Subsection 4.3) data.

\subsection{Data description}

We use multiple sources of United States Bureau of Labour Statistics (BLS) data to estimate the Phillips curve. Since a time-series of state-level Consumer Price Index (CPI) data is not available, we calculate price inflation by using CPI-U (i.e CPI for all Urban Consumers) data by Census region. In particular, we use the four-Census regions as described by BLS and mapped all states to the four-Census accordingly. The data are available on a monthly basis. The monthly state unemployment rates are calculated from the monthly Current Population Survey (CPS or household survey). Data on state level wages are constructed using average hourly nominal wages from the Centre for Economic Policy Research (CEPR) database, employing CEPR uniform extracts of CPS-ORG (the Outgoing Rotation Group) data.

Unlike some other studies, we do not use short-term and long-term unemployment measures due to significant measurement changes at the BLS database, and because the models we examine do not call for the distinction. Productivity data are also from BLS. We use business sector productivity, available on a monthly basis at national level. Where we employ a Hodrick-Prescott filter to obtain trend labour productivity growth we use the conventional value for the smoothing parameter with monthly data (14400). Table 1 abridges the sources of the variables we use.

Due to the panel nature of our data, Table 2 shows two variations of descriptive statistics to illustrate distribution over states and time for the unemployment variable $u_{t}$. The upper part of the table shows the minimum (min), maximum ( $\max$ ), mean and standard deviation (SD) of mean state level unemployment, whereas the bottom part of the table shows the means of the summary statistics over time.

To better portray the distribution abridged in Table 2, Figure 1 presents the data for each state in the sample. For an interactive version of the figure illustrating time and cross-section points of choice, see the online version of the paper. We do not present a figure of our wage rate variables, as being a monthly rate of change variable the data are noisy and hard to disentangle. 


\begin{tabular}{|c|c|c|c|}
\hline & Description & Source & Notes \\
\hline$w$ & $\begin{array}{l}\text { Average hourly nominal } \\
\text { wage rates }\end{array}$ & $\begin{array}{l}\text { CEPR uniform extract } \\
\text { of CPS-ORG data }\end{array}$ & $\begin{array}{c}\text { Usual hourly earnings for hourly } \\
\text { and non-hourly workers. We have } \\
\text { constructed those variables manually. } \\
\text { Monthly state data. }\end{array}$ \\
\hline$u$ & $\begin{array}{c}\text { The state unemployment rates / } \\
\text { Unemployment levels / } \\
\text { Employment levels }\end{array}$ & CPS & Monthly state data \\
\hline$p$ & CPI-U & $\begin{array}{l}\text { BLS series by } \\
\text { Census Region }\end{array}$ & $\begin{array}{l}\text { We use the } 4 \text { Census regions as described in } \\
\text { BLS and mapped all states to these } \\
\text { Census regions accordingly. Monthly data. }\end{array}$ \\
\hline$\Delta w p g$ & $\Delta w p g_{i, t}=\Delta w_{i, t}-\Delta p_{i, t}-g_{t}$ & Authors' elaboration & $\begin{array}{l}\text { Monthly productivity (country level). } \\
\text { Business sector productivity BLS }\end{array}$ \\
\hline
\end{tabular}

Table 1: Data notes

\begin{tabular}{cc}
\hline \multicolumn{2}{c}{ Distribution over States } \\
\hline Descriptive Statistic & Value \\
Min $\left[\overline{\mathbf{u}}_{1, t}, \ldots, \overline{\mathbf{u}}_{51, t}\right]$ & 1.238 \\
Mean $\left[\overline{\mathbf{u}}_{1, t}, \ldots, \overline{\mathbf{u}}_{51, t}\right]$ & 1.730 \\
Max $\left[\overline{\mathbf{u}}_{1, t}, \ldots, \overline{\mathbf{u}}_{51, t}\right]$ & 2.053 \\
SD $\left[\overline{\mathbf{u}}_{1, t}, \ldots, \mathbf{u}_{51, t}\right]$ & 0.198 \\
& \\
\hline \multicolumn{2}{c}{ Distribution over Time } \\
Descriptive Statistic & Value \\
Mean $\left[\right.$ Min $\mathbf{u}_{1, t}, \ldots$, Min $\left.\mathbf{u}_{51, t}\right]$ & 1.1804 \\
Mean $\left[\right.$ Max $\mathbf{u}_{1, t}, \ldots$, Max $\left.\mathbf{u}_{51, t}\right]$ & 2.3289 \\
Mean $\left[\right.$ SD $\mathbf{u}_{1, t}, \ldots$, SD $\left.\mathbf{u}_{51, t}\right]$ & 0.2791 \\
\hline
\end{tabular}

Table 2: Descriptive statistics for unemployment

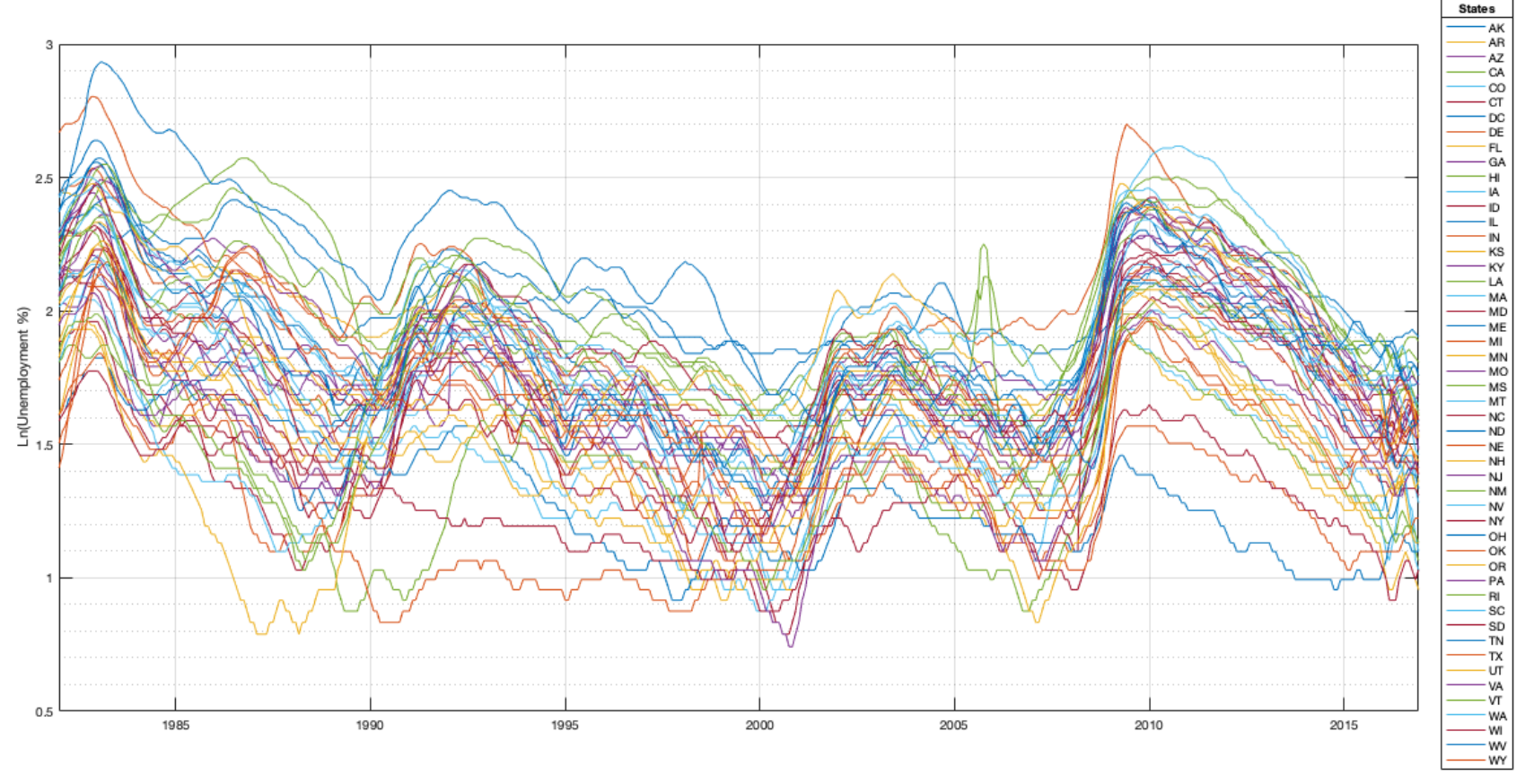

Figure 1: Disaggregate unemployment per State: 1982 - 2016 


\subsection{Aggregate data}

Galí (2011) reports that on aggregate quarterly US data, an $\operatorname{AR}(2)$

$$
u_{t}=0.22^{* *}+1.66^{* *} u_{t-1}-0.70^{* *} u_{t-2}+\varepsilon_{t}
$$

where $^{* *}$ indicates $5 \%$ significance $(* 10 \%)$ is a good model for the period from 1948Q1 to 2009Q3. Our data -defined as in Galí (2011): earnings-based measure- are monthly and cover 1982M1 to 2016M12. Figure 2 shows the aggregate monthly data over the sample we use, together with the average of our state-level data. The unweighted state-level data average to a lower value than the aggregate and are smoother, but follow a similar trend. In contrast to e.g. the European data, where there are evident trends and mean shifts, it is more plausible that the data are stationary. More formally, unit root tests reject the null of non-stationarity (e.g. $\operatorname{ADF}(6)=-3.22, p$-value 0.019) and cannot reject stationarity (KPSS with Newey-West bandwidth $16=0.34$, $5 \%$ critical value 0.46$)$.

The natural rate $u_{n}$ could in principle be modelled by a band-pass filter or a univariate state-space model as an unobservable variable as in Orlandi et al. (2017), by a structural state-space model, or by using natural rate drivers. All present problems and moreover in each case are impracticable to construct at state level. Bandpass filters are particularly arbitrary and suffer from end-point biases, as do univariate state-space models, and state-level estimates are likely to be very poorly determined. More structural state-space models assume the relationship we are trying to estimate, as they back out $u_{n}$ as an unobservable in the Phillips curve. Structural models as in Layard et al. (1991) have not been seriously estimated since the 1980s, essentially because the empirical programme to estimate a structural model of $u_{n}$ was a failure (see Jackman, 1998, for a discussion of some aspects). And state-level drivers would in any case be hard to find, notwithstanding the empirical difficulty of satisfactorily estimating such models. So, given the evidence for stationarity, we are content to follow Galí, to assume the natural rate is constant and work with the log level.

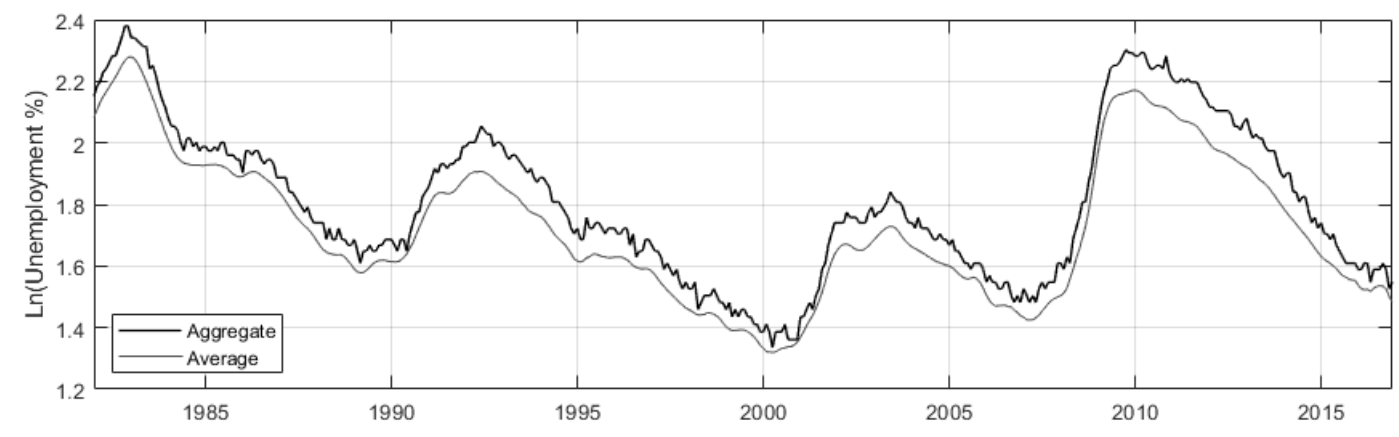

Figure 2: Average and aggregate unemployment: 1982 - 2016

Corresponding to Galí's specification, over these two periods, a monthly $\mathrm{AR}(6)$ exhibit some autocorrelation at annual frequencies but have similar properties to his quarterly results. We also adopt this dynamic specification for the disaggregated data. A simplified version for our 1982 to 2016 sample is

$$
u_{t}=0.02^{* * *}+1.097^{* * *} u_{t-1}-0.111^{* * *} u_{t-6}+\varepsilon_{t} .
$$

As in Gali (2011), this process is persistent but stationary. The impulse responses to a shock are similar to Galí's when adjusted for the frequency. Informed by this estimated AR process, we estimate (4.1) and (4.2),

$$
\begin{gathered}
\Delta w_{t}=\alpha_{1}+\gamma \Delta p_{t-1}+\psi_{1,0} u_{t}+\psi_{1,1} u_{t-5}+\varepsilon_{t}, \\
\Delta w p g_{t}=\alpha_{2}+\beta \Delta w p g_{t-1}+\psi_{1,0} u_{t}+\psi_{2,1} u_{t-5}+\varepsilon_{t},
\end{gathered}
$$

where in both cases we expect $\psi_{i, 0}<0$ and $\psi_{i, 1}>0$. Galí used two alternative definitions for the indexation 
variable, quarterly inflation and year-on-year inflation, which in our monthly case is $p_{t}-p_{t-12}\left(\Delta^{12} p_{t}\right)$, lagged one month. His preferred quarterly specification (2.4) estimated with quarterly data over 1964Q1 to $2007 \mathrm{Q} 4$ for average hourly earnings of production and non-supervisory employees with the level of unemployment and the former inflation series returned estimates of

$$
\Delta w_{t}=\alpha+0.503^{* *} \Delta p_{t-1}-0.334^{* *} u_{t}+0.294^{* *} u_{t-1}
$$

Re-estimated with monthly data over the same sample, but taking account of the estimated AR process and using $\ln (U)$ we obtain

$$
\Delta w_{t}=\alpha+0.0296^{* * *} \Delta p_{t-1}-0.000 u_{t}-0.000 u_{t-5}
$$

Estimated over the sample of this study (19824M1 to 2016M12) using $\ln (u)$ we obtain

$$
\Delta w_{t}=\alpha+0.052 \Delta p_{t-1}-0.026 u_{t}+0.025 u_{t-5}
$$

So the aggregate monthly data do not support this specification. However, Galí obtains

$$
\Delta w_{t}=\alpha+0.687^{* *} \Delta p_{t-1}^{12}-0.552^{* *} u_{t}+0.453^{* *} u_{t-1}
$$

using year-on-year annual price inflation, and for Galí's sample we obtain

$$
\Delta w_{t}=\alpha+0.635 \Delta p_{t-1}^{12}-0.0064^{* * *} u_{t}+0.0047^{* * *} u_{t-5}
$$

which is more consistent, although the estimates of the unemployment are small. For our sample, however, the estimates are yet smaller and entirely insignificant.

$$
\Delta w_{t}=\alpha+0.280^{* * *} 12 \Delta p_{t-1}^{12}-0.000 u_{t}+0.001 u_{t-5}
$$

For the real-wage specification with the same lag structure for unemployment we obtain

$$
\Delta w p g_{t}=\alpha+0.739^{*} \Delta w p g_{t-1}+0.002 u_{t}-0.004 u_{t-5}
$$

where the unemployment terms are again small and insignificant.

Essentially, it does not appear that the aggregate monthly data support this reduced-form specification over the more recent sample available to us at a disaggregated level.

\subsection{Panel results}

By contrast, we are able to obtain results consistent with the theory using the disaggregated data. For reference, we plot the average of the state level price inflation, the log-level of the wage and the productivity-adjusted 'real-wage' inflation rates together with the aggrgegate data in Figures 3, 4 and 5. The price inflation data differ but are closely aligned. The wage data however are much more volatile at the average state-level than the aggregate, as can be seen in the chart of the level. There is also an average level difference (scaled away in the chart) and an average growth difference for the period up to 1990. The productivity-adjusted real wage $w p g$ is constructed using aggregate productivity data as state-level data on output (or productivity) are unavailable at a monthly frequency, and also may be taken to more closely represent the underlying trend. These data are reported as inflation rates, which emphasises the volatility relative to the aggregate following from the wage measure.

As with the aggregate data, we estimate (4.1) and (4.2). We use year-on-year inflation for the indexation series.

We begin by testing for cross-sectional dependence using the CSD test developed in Pesaran (2004). This is 


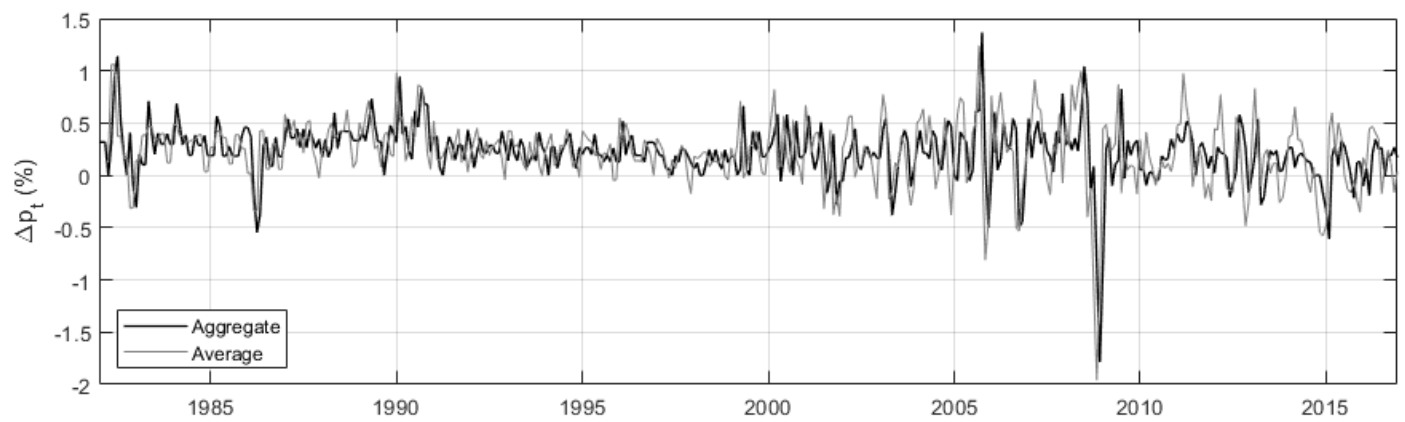

Figure 3: Average and aggregate inflation rate: 1982 - 2016

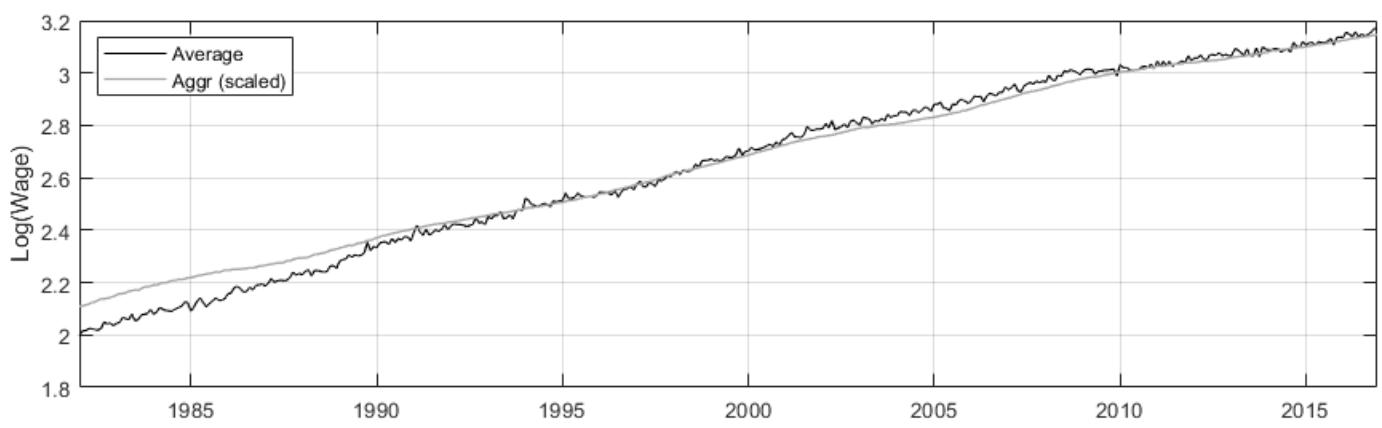

Figure 4: Average log(wage): 1982 - 2016

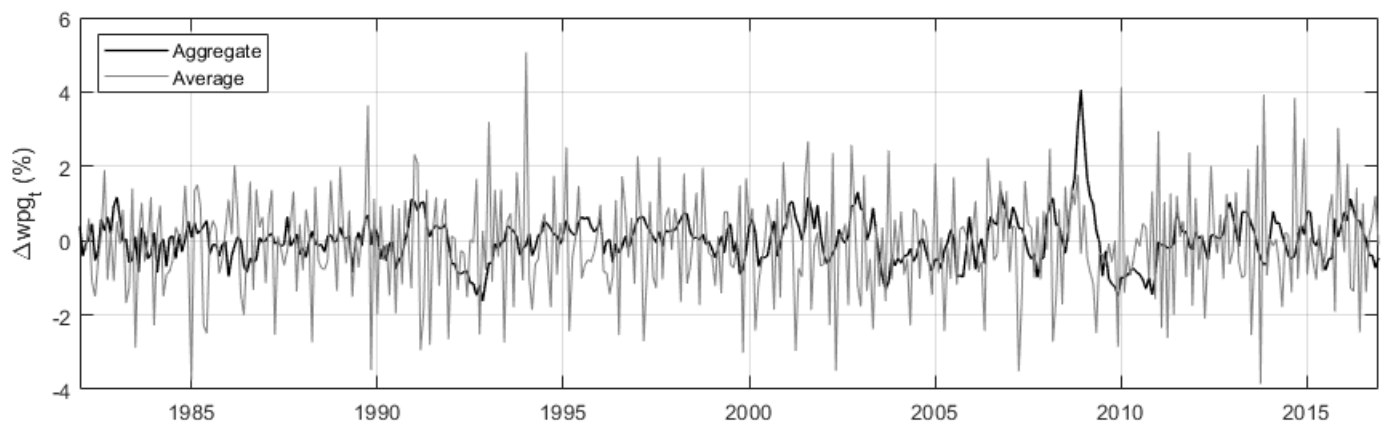

Figure 5: Average real-wage inflation rate: 1982 - 2016 
based on the set of seemingly unrelated regressions given in (3.1) and repeated here without the assumption of the factor structure in the errors

$$
y_{i t}=\beta_{0 i}+\beta_{1 i} y_{i, t-1}+\boldsymbol{\beta}_{2 i}^{\prime} \boldsymbol{x}_{i t}+\boldsymbol{\beta}_{3 i}^{\prime} \boldsymbol{z}_{i t}+u_{i t}
$$

The CSD test statistic asymptotically follows $N(0,1)$, and is computed:

$$
C S D=\sqrt{\frac{2 T}{N(N-1)}}\left(\sum_{i=1}^{N-1} \sum_{j=i+1}^{N} \hat{\rho}_{i j}\right),
$$

where

$$
\hat{\rho}_{i j}=\frac{\sum_{t=1}^{T} \hat{u}_{i t} \hat{u}_{j t}}{\left(\sum_{t=1}^{T} \hat{u}_{i t}^{2}\right)^{1 / 2}\left(\sum_{t=1}^{T} \hat{u}_{j t}^{2}\right)^{1 / 2}}
$$

are the sample estimates of the pairwise correlations of the residuals. Applying this to (4.1) and (4.2) we strongly reject ( $p$-values equal to 0.000 in all cases) the null hypothesis of no cross-sectional dependence.

We then estimate the model using four methods, in each case instrumenting $u_{t}$ with four instruments sets, using up to four lags of $u_{t}$. For reference, we report results using simple pooled OLS, a standard fixed effects model (FE) and a standard mean-group specification (MG) (Pesaran and Smith, 1995), as well as our preferred efficient CCE estimator (CCE). As there is no lagged dependent variable, the OLS and FE estimates do not suffer from the bias identified by Pesaran and Smith (1995), but do potentially lead to misleading inference and inconsistency (Pesaran M. H., 2006). We instrument the endogenous variables with a prior regression as in Harding and Lamarche (2011). The results are reported in Table 3.

\begin{tabular}{|c|cccc|cccc|}
\hline & \multicolumn{4}{|c|}{ Instruments: lag 1 } & \multicolumn{4}{c|}{ Instruments: lags 2, 3 } \\
\cline { 2 - 8 } & OLS & FE & MG & CCE & OLS & FE & MG & CCE \\
\hline$u_{t}$ & $-0.076^{* * *}$ & $-0.084^{* * *}$ & $-0.092^{* * *}$ & $-0.156^{* * *}$ & $-0.075^{* * *}$ & $-0.083^{* * *}$ & $-0.096^{* * *}$ & $-0.157^{* * *}$ \\
$u_{t-5}$ & $0.049^{* * *}$ & $0.044^{* * *}$ & $0.049^{* * *}$ & $0.063^{* * *}$ & $0.048^{* * *}$ & $0.043^{* * *}$ & $0.054^{* * *}$ & $0.064^{* * *}$ \\
$\Delta^{12} p_{t-1}$ & $0.3492^{* * *}$ & $0.3288^{* * *}$ & $0.3132^{* * *}$ & $0.5604^{*}$ & $0.3492^{* * *}$ & $0.3288^{* * *}$ & $0.3096^{* * *}$ & 0.5064 \\
\hline & \multicolumn{3}{|c}{ Instruments: lags 1-3 } & & \multicolumn{3}{c}{ Instruments: lags 1-4 } \\
\cline { 2 - 9 } & OLS & FE & MG & CCE & OLS & FE & MG & CCE \\
\hline$u_{t}$ & $-0.073^{* * *}$ & $-0.081^{* * *}$ & $-0.094^{* * *}$ & $-0.166^{* * *}$ & $-0.072^{* * *}$ & $-0.080^{* * *}$ & $-0.092^{* * *}$ & $-0.164^{* * *}$ \\
$u_{t-5}$ & $0.046^{* *}$ & $0.042^{*}$ & $0.051^{*}$ & $0.072^{* *}$ & $0.045^{*}$ & $0.040^{*}$ & $0.050^{*}$ & $0.071^{* *}$ \\
$\Delta^{12} p_{t-1}$ & $0.3492^{* * *}$ & $0.3288^{* * *}$ & $0.3132^{* * *}$ & 0.5268 & $0.3492^{* * *}$ & $0.3288^{* * *}$ & $0.3132^{* * *}$ & $0.5352^{*}$ \\
\hline
\end{tabular}

OLS indicates pooled estimates, FE fixed effects, $M G$ mean group, CCE common correlated effects.

***, ${ }^{* *}$ and ${ }^{*}$ indicate $1 \%, 5 \%$ and $10 \%$ significance respectively.

Table 3: A backward looking specification for a (nominal) Augmented New Keynesian Wage Phillips Curve

The results are largely invariant to the instrument set. The OLS, FE and MG estimates are all similar. However, the preferred CCE estimates differ, with an impact from unemployment that is roughly double the size than in the other cases, implying an economically significantly steeper Phillips curve (wages are roughly twice as responsive to unemployment). Moreover, the price indexation term is around two thirds higher than the less efficient results, albeit only marginally significant in two cases. The data are scaled to make them comparable to those in Galí. Although estimated with a different data set, frequency and sample, the CCE results are in fact broadly comparable to Galí's. The main difference is that the net impact of unemployment is larger using the disaggregated data, while the inflation indexation term is very similar. As we have established that the aggregate results are not roubust to the sample period, so this is particularly useful.

Table 4 reports the results from the Orlandi et al. (2017) real-wage rigidity specification using actual (aggregate) productivity. The results using HP filtered productivity (using the conventional monthly smoothing parameter of 14400) are very similar and are not reported for brevity. In this case (following their notation), the coefficient on the lagged productivity adjusted real-wage growth term is given by $\beta_{0}=\frac{\beta}{1+\frac{(\theta-1) \phi}{\gamma(1-p h i)}}$. If the parameter 
determining real-wage inertia $\phi=0$, implying no real-wage rigidity, then $\beta_{0}$ will be close to but less than one. In this case the dynamic bias due to Pesaran and Smith (1995) does hold, in addition to any issues flowing from common correlated errors. As above, the results are largely invariant to the instrument set. The results for OLS, FE and MG (the latter not subject to dynamic bias) are similar, although the estimate of the coefficient on the lagged dependent variable are very different from the CCE estimates. But crucially, the OLS, FE and MG results are each grossly inconsistent with the theory as the estimated parameter $\hat{\beta}_{0}<0$, which can only be the case if the discount factor $\hat{\beta}$ is itself negative, which is obviously inadmissible.

By contrast, in the CCE case, the coefficient is close to unity. We cannot reject a value such as 0.98 on a two-sided test, so the results are consistent with even quite substantial values of the discount factor (recall that we are using monthly data) and no real-wage rigidity. The implication is that we cannot reject the hypothesis that the discount factor is close to unity and real wages are fully flexible. So our CCE estimator is necessary in order to produce meaningful results that have a sensible economic interpretation.

\begin{tabular}{|c|cccc|cccc|}
\hline & \multicolumn{4}{|c|}{ Instruments: lag 1 } & \multicolumn{4}{c|}{ Instruments: lags 2, 3 } \\
\cline { 2 - 8 } & OLS & FE & MG & CCE & OLS & FE & MG & CCE \\
\hline$u_{t}$ & $-0.130^{* * *}$ & $-0.138^{* * *}$ & $-0.152^{* * *}$ & $-0.162^{* * *}$ & $-0.128^{* * *}$ & $-0.136^{* * *}$ & $-0.152^{* * *}$ & $-0.163^{* * *}$ \\
$u_{t-5}$ & $0.092^{* * *}$ & $0.084^{* * *}$ & $0.094^{* *}$ & $0.099^{* * *}$ & $0.089^{* * *}$ & $0.082^{* *}$ & $0.094^{* * *}$ & $0.099^{* * *}$ \\
$w p g_{t-1}$ & $-0.496^{* * *}$ & $-0.496^{* * *}$ & $-0.492^{* * *}$ & $1.002^{* * *}$ & $-0.496^{* * *}$ & $-0.496^{* * *}$ & $-0.492^{* * *}$ & $1.002^{* * *}$ \\
\hline & \multicolumn{3}{|c}{ Instruments: lags 1-3 } & & \multicolumn{4}{c}{ Instruments: lags 1-4 } \\
\cline { 2 - 9 } & OLS & FE & MG & CCE & OLS & FE & MG & CCE \\
\hline$u_{t-1}$ & $-0.126^{* * *}$ & $-0.134^{* * *}$ & $-0.151^{* * *}$ & $-0.169^{* * *}$ & $-0.124^{* * *}$ & $-0.132^{* * *}$ & $-0.150^{* * *}$ & $-0.167^{* * *}$ \\
$u_{t-5}$ & $0.088^{* * *}$ & $0.080^{* * *}$ & $0.094^{* *}$ & $0.105^{* * *}$ & $0.086^{* * *}$ & $0.078^{* *}$ & $0.092^{* *}$ & $0.104^{* * *}$ \\
$w p g_{t-1}$ & $-0.496^{* * *}$ & $-0.496^{* * *}$ & $-0.492^{* * *}$ & $1.002^{* * *}$ & $-0.496^{* * *}$ & $-0.496^{* * *}$ & $-0.492^{* * *}$ & $1.002^{* * *}$ \\
\hline
\end{tabular}

Notes as Table 3 .

Table 4: A backward looking specification for a real New Keynesian Wage Phillips Curve (actual productivity)

In Section 3 we proposed our method on econometric grounds, and have established that it makes a material difference to estimates and in the real-wage rigidity case is necessary for economically interpretable results to emerge. Next, we apply a further diagnostic with the augmented weighted-CSD test of Juodis and Reese (2018). That is to avoid divergence of the Pesaran (2004) CSD test statistic -as length of the time dimension of the sample grows- and thus avoid mistakenly rejecting the null of no cross-sectional dependence. In particular, as Juodis and Reese (2018) suggest, the weighted CSD test statistic is estimated as

$$
C S D_{W}=\left(\frac{1}{N T} \sum_{i=1}^{N} \sum_{t=1}^{T} \hat{u}_{i t}^{2} w_{i}^{2}\right)^{-1}\left(\sqrt{\frac{2}{T N(N-1)}} \sum_{t=1}^{T} \sum_{i=2}^{N} \sum_{j=1}^{i-1} w_{i} \hat{u}_{i t} w_{j} \hat{u}_{j t}\right)
$$

and asymptotically follows $N(0,1)$, with $\mathbf{w}=\left[w_{1}, w_{2}, \ldots, w_{n}\right]$ being a vector of weights, with $w_{i}$ corresponding to State $i \in I=\{1,2, \ldots, 51\}, j \in I, j \neq i$, obtained from a Rademacher distribution. Following the suggestions of Juodis and Reese (2018, see Remark 6, p.21), 30 weight vectors were randomly generated, and the distribution of test statistics can be approximated with a single statistic as

$$
\overline{C S D}_{W}=\frac{1}{\sqrt{G}} \sum_{g=1}^{G} C S D_{W}^{(g)}
$$

According to the results, the four models tested in this study (OLS, FE, MG, CCE) had statistics of 1.772 , 1.548, 1.537 and 0.842 for eq. (4.1) and 1.998, 1.994, 1.791 and 0.114 for eq. (4.2). Given the use of CSD tests applied as ex-post diagnostic tools as means of validating the use of models (see, e.g., among others, the studies of Holly et al., 2010; Everaert and Pozzi, 2014; Bailey et al., 2016), based on the obtained statistics, the validity of CCE is still confirmed over the other three candidate models in both specifications.

Thus, we find that two alternative specifications for a NKPC may be estimated using panel data, in contrast 
to the aggregate data. The standard inefficient and potentially inconsistent methods produce similar results that are economically different from those produced by the CCE method. Somewhat remarkably, the CCE results are close to those produced by Galí (2011) using entirely different data sets and samples. In the case of the real-wage rigidity specification, only the CCE estimates are theoretically admissible, and point to full price flexibility.

\section{Conclusions}

The Phillips curve remains at the centre of New Keynesian DSGE models of the type widely used as macroeconomic benchmarks and for policy purposes. The precise specification of the wage adjustment process is crucial for welfare-based policy evaluation. If there is heterogeneity in dynamics at the level of aggregation (the State in our case), aggregation may lead to substantial bias in dynamics. Thus, it may be useful to examine disaggregated data sets, in order to unpick the average parameters. In addition, unemployment and wages are likely to be simultaneously determined, which creates endogeneity, and there are likely to be be common correlated errors, both further sources of potential large biases.

We therefore examine two alternative non-nested reduced-form versions of a New Keynesian wage Phillips curve using monthly US state-level data for the period 1982-2016, taking account of the heterogeneity in dynamics by mean-group estimation, endogeneity of unemployment by instrumentation, and the presence of common correlated effects (CCE). This is an exercise that has not previously been undertaken. One New Keynesian Wage Phillips Curve embodying nominal rigidity is augmented by inflation, and another operates with real-wage rigidity. In the former case, the theoretically superior CCE estimator provides estimates that are economically and statistically significant from the results using the conventional methods (all accounting for endogeneity) with a steeper Phillips curve (wages being more responsive to unemployment) and higher levels of indexation. In the latter, only the specification estimated using the CCE estimator is theoretically admissible, but implies complete real-wage flexibility. Although we tentatively conclude that on economic grounds the specification with nominal wage rigidity is preferred, our primary aim in this paper is not to choose between these two or other models, a task we leave to others or future research, but to demonstrate that ignoring cross-sectional dependence and endogeneity are serious and material omissions. We have applied this in an important context (the Phillips curve), but hope that other researchers in similar econometric environments will follow our methodological lead.

\section{Acknowledgements}

The Authors wish to thank the co-editor, Erricos John Kontoghiorghes, and two anonymous referees for many insightful comments, which have led to substantial improvements in the paper. All errors are our own.

\section{References}

Aaronson, D. And D. Sullivan (2000): "Recent Evidence on the Relationship Between Unemployment and Wage Growth," WP 2000-27, Federal Reserve Bank of Chicago.

Anderson, T. W. And C. Hsiao (1982): "Formulation and estimation of dynamic models using panel data," Journal of Econometrics, 18, 47-82.

Arellano, M. And S. Bond (1991): "Some Tests of Specification for Panel Data: Monte Carlo Evidence and an Application to Employment Equations," Review of Economic Studies, 58, 277-297.

Bailey, N., S. Holly, And M. H. Pesaran (2016): "A two-stage approach to spatio-temporal analysis with strong and weak cross-sectional dependence," Journal of Applied Econometrics, 31, 249-280. 
Byrne, J. P., A. Kontonikas, And A. Montagnoli (2013): "International Evidence on the New Keynesian Phillips Curve Using Aggregate and Disaggregate Data," Journal of Money, Credit and Banking, $45,913$.

Chudik, A. And M. H. Pesaran (2015): "Common correlated effects estimation of heterogeneous dynamic panel data models with weakly exogenous regressors," Journal of Econometrics, 188, 393-420.

CoAkley, J., A.-M. Fuertes, And R. Smith (2006): "Unobserved heterogeneity in panel time series models," Computational Statistics and Data Analysis, 50, 2361-2380.

Evans, G. (1985): "Bottlenecks and the Phillips Curve: A Disaggregated Keynesian Model of Inflation, Output, and Unemployment," Economic Journal, 95, 345-357.

Everaert, G. And L. POzzI (2014): "The predictability of aggregate consumption growth in OECD countries: a panel data analysis," Journal of Applied Econometrics, 29, 431-453.

Friedman, M. (1968): "The Role of Monetary Policy," American Economic Review, 1-17.

Galí, J. (2011): "The return of the wage Phillips curve," Journal of the European Economic Association, 9, 436-61.

Hansen, B. (1970): "Excess Demand, Unemployment, Vacancies, and Wages," The Quarterly Journal of Economics, 84, 1-23.

Harding, M. And C. LAmArche (2011): "Least squares estimation of a panel data model with multifactor error structure and endogenous covariates," Economics Letters, 111, 197-199.

Holly, S., M. H. Pesaran, And T. Yamagata (2010): "A spatio-temporal model of house prices in the USA," Journal of Econometrics, 158, 160-173.

Imbs, J., E. Jondeau, And F. Pelgrin (2007): "Aggregating Phillips Curves," CEPR Discussion Papers 6184, C.E.P.R. Discussion Papers.

Imbs, J., H. Mumtaz, M. O. Ravn, And H. Rey (2005): "PPP strikes back: Aggregation and the real exchange rate," The Quarterly Journal of Economics, 120, 1-43.

JACKMAN, R. (1998): "European Unemployment: Why is it so High and What Should be Done About it?" in Unemployment and the Australian Labour Market, ed. by G. Debelle and J. Borland, Reserve Bank of Australia.

Juodis, A. And S. ReEse (2018): "The Incidental Parameters Problem in Testing for Remaining Cross-section Correlation," arXiv preprint arXiv:1810.03715.

Kapetanios, G., M. H. Pesaran, and T. Yamagata (2011): "Panels with non-stationary multifactor error structures," Journal of Econometrics, 160, 326-48.

Kumar, A. And P. M. Orrenius (2014): "A closer look at the Phillips curve using state-level data," Federal Reserve Bank of Dallas Working Papers 1409.

Layard, R., S. Nickell, And R. JaCkman (1991): Unemployment: Macroeconomic Performance and the Labour Market, Oxford University Press.

Leduc, S. And D. J. Wilson (2017): "Has the Wage Phillips Curve Gone Dormant?" FRBSF Economic Letter 2017-20, FRB San Francisco.

Lipsey, R. G. (1960): "The Relation between Unemployment and the Rate of Change of Money Wage Rates in the United Kingdom, 1862-1957: A Further Analysis," Economica, 27, 1-31. 
M J Luengo-Prado, N. R. And V. Sheremirov (2017): "Sectoral Inflation and the Phillips Curve: What Has Changed since the Great Recession?" Current Policy Perspectives 17-5, FRB Boston.

Nickell, S. (1981): "Biases in Dynamic Models with Fixed Effects," Econometrica, 49, 1417-26.

Orlandi, F., W. Roeger, And A. Thum-Thysen (2017): "The return of the European wage Phillips curve," Mimeo, European Central Bank.

Pesaran, M. H. (2004): "General diagnostic tests for cross section dependence in panels," CESifo Working Paper Series No. 1229; IZA Discussion Paper No. 1240.

Pesaran, M. H., Y. Shin, And R. P. Smith (1999): "Pooled Mean Group Estimation of Dynamic Heterogeneous Panels," Journal of the American Statistical Association, 94, 621-634.

Pesaran, M. H. AND R. Smith (1995): "Estimating long-run relationships from dynamic heterogeneous panels," Journal of Econometrics, 79-113.

Pesaran M. H. (2006): "Estimation and Inference in Large Heterogeneous Panels with a Multifactor Error Structure," Econometrica, 74, 967-1012.

Phelps, E. S. (1967): "Phillips Curves, Expectations of Inflation and Optimal Unemployment over Time," Economica, 34, 254-81.

Phillips, A. W. (1958): "The Relation Between Unemployment and the Rate of Change of Money Wage Rates in the United Kingdom, 1861-1957," Economica, 25, 283.

Phillips, P. C. B. AND D. Sul (2003): "Dynamic panel estimation and homogeneity testing under cross section dependence," The Econometrics Journal, 6, 217-59.

Robertson, D. And J. Symons (1992): "Some Strange Properties of Panel Data Estimators," Journal of Applied Econometrics, 7, 175-189.

Smith, C. (2014): "The Effect of Labor Slack on Wages: Evidence from State-Level Relationships," Feds notes, Board of Governors of the Federal Reserve System (U.S.).

Woodford, M. (2003): Interest and Prices, Princeton, N.J.: Princeton University Press. 